\title{
Ethnic Differences in the Impact of Parental Myopia: Findings from a Population-Based Study of 12-Year-Old Australian Children
}

\author{
Jenny M. Ip, ${ }^{1}$ Son C. Huynh, ${ }^{1}$ Dana Robaei, ${ }^{1}$ Katbryn A. Rose, ${ }^{2}$ Ian G. Morgan, ${ }^{3,4}$ \\ Wayne Smith, ${ }^{5}$ Annette Kifley, ${ }^{1}$ and Paul Mitchell ${ }^{1}$
}

Purpose. To examine the influences of ethnicity, parental myopia, and near work on spherical equivalent refraction (SER) and axial length (AL) in a population-based sample of 12-yearold Australian children.

Meruods. Year-7 children in the Sydney Myopia Study ( $n=$ $2353,75.3 \%$ response) underwent an ophthalmic examination including cycloplegic autorefraction ( $1 \%$ cyclopentolate) and ocular biometry (IOLMaster; Carl Zeiss Meditec GmbH, Jena, Germany). Data for parental myopia, ethnicity, near work, and outdoor activities were derived from questionnaires and were available for 1781 children. Optical prescriptions of parents were sought if the spectacles were used.

Resunts. The prevalence of myopia in the children increased with the number of myopic parents $(7.6 \%, 14.9 \%$, and $43.6 \%$ for no, one, or two myopic parents). In parallel, the mean SER (나을 of the mean) was more negative $(0.70 \pm 0.08,0.34 \pm$ 0.09 , and $-0.55 \pm 0.34 \mathrm{D}$ ), and the mean $\mathrm{AL}$ was longer $(23.32 \pm 0.05,23.44 \pm 0.06$, and $23.62 \pm 0.16 \mathrm{~mm})$ after adjustment for demographic and environmental factors. In multivariate analyses, odds of childhood myopia did not change with higher levels of near work (odds ratio [OR] = $1.01 ; 95 \%$ confidence interval $[\mathrm{CI}]=0.99-1.03$ ). Interactions between parental myopia and ethnicity were significant for SER and AL (both $P<0.0001$ ), reflecting greater decreases in SER and greater increases in AL with the number of myopic parents in the children of East Asian ethnicity than in the children of European Caucasian ethnicity. In the nonmyopic children, there was no association between parental myopia and $\mathrm{AL}$.

From the 'Centre for Vision Research (Department of Ophthatmology and Westmeald Millennium Institute), University of Sydney, and the Vision Co-operative Research Centre, University of New South Wales, Sydney Australia; the "School of Applied Vision Sciences, Faculty of Health Sciences, University of Sydney, Sydney, Australia; the ${ }^{3}$ ARC (Australian Research Council) Centre of Excellence in Vision Science and the ${ }^{i}$ Research School of Biological Sciences, Australian National University, Canberra, Australia; and the ${ }^{5}$ Centre for Clinical Epidemiology and Biostatistics, the University of Newcastle, Australia.

Supported by Australian National Fealth and Medical Research Council Grant 253732; the Westmead Millennium Institute, University of Sydney; and the Vision Co-operative Research Centre, University of New South Wales, Sydney.

Submitted for publication June 27, 2006; revised October 4 and December 8, 2006, and January 15 and February 16, 2007; accepted April 2, 2007.

Disclosure: J.M. Ip, None; S.C. Huynh. None; D. Robaei, None; K.A. Rose, None; I.G. Morgan, None; W. Smith, None; A. Kifley, None; P. Mitchell, None

The publication costs of this article were defrayed in part by page charge payment. This article must therefore be marked "advertisement" in accordance with 18 U.S.C. $\$ 1734$ solely to indicate this fact.

Corresponding atuthor: Paul Mitchell, Department of Ophthalmology, Centre for Vision Research, Westmead Hospital, Hawkesbury Road, Westmead, NSW, Austrulia, 2145; paul mitchell@wmi.usyd.edu.au.
Conclusions. In this sample, parental myopia was associated with more myopic SER and longer AL, with significant ethnic interactions. (Invest Ophthalmol Vis Sci. 2007;48:2520-2528) DOI:10.1167/iovs.06-0716

F pidemiologic studies have provided considerable data on D the familial and environmental associations of myopia in children. Characteristically high prevalence rates of myopia in children have been found in East Asia, ${ }^{1-7}$ particularly in urban settings in populations of both Fast Asian ${ }^{1-4}$ and Sonth Asian ethnicity. ${ }^{7}$ Associations of myopia in children include parental myopia, increased near work, and higher schooling. ${ }^{8-13}$

Parental myopia has been associated with a higher prevalence and a greater likelihood of childhood myopia in both European Caucasian ${ }^{14,15}$ and East Asian children. ${ }^{16} 17$ Given that parents may foster patterns of behavior, interests, and academic goals in their children, it is uncertain whether this association with childhood nyopia is genetic in origin or reflects environmental influences operating within the family unit

The axial length (AL) of myopic eyes is generally greater than that of nonmyopic eyes-predominantly the result of a deeper vitreous chamber, ${ }^{2,13,16,18,19}$ Zadnik et al. ${ }^{20}$ reported that, even before the onset of myopia, children with a family history of myopia had longer eyes, a finding that they interpreted as evidence of a genetic predisposition to the development of childhood myopia, although this interpretation has been challenged. ${ }^{21,22}$ These observations have been tested in only one other study, ${ }^{23}$ which did not replicate the findings.

In this population-based study, we sought to examine the association of myopia and refraction in parents, with refraction and $\mathrm{AL}$ in their children, and to determine the presence of possible interactions between ethnicity, parental myopia, and near work in childhood refraction.

\section{Methods}

\section{Study Population}

The Sydney Myopia Study is a population-based survey of eye health in school children resident in the Sydney metropolitan ares in Australia. and forms part of the Sydney Childhood Eye Study, in which childhood eye conditions are being examined across a range of age groups Approval for the study was obtained from the University of Sydncy Fuman Research Ethics Committee, the New South Wales Departmen of Education, and the Catholic Education Office. The study adhered to the tenets of the Declaration of Helsinki.

Detailed study methods have been described elsewhere ${ }^{2.4}$ Briefly the study was of a random cluster design, wherein secondary schools across the Sydney metropolitan region were stratified by socioeco nomic status (SES), and 21 secondary (high) schools were tandonly selected, to provide a representative sample. $\Lambda$ proportional mix of government and private/religious schools was included. All year-7 students were invited to participate. For ethical reasons we were unable to collect any demographic data for the children who did not 
participate in the study. Therefore, some caution should be exercised in the generalization of our findings to the whole population. Written informed consent was obtained from at least one parent after explanation of the nature of the study, and verbal consent was obtained from each child before examination.

\section{Examination}

After instillation of amethocaine, cycloplegia was induced with cyclopentolate $1 \%$ ( 1 drop), and autorefraction was performed at -25 minutes after the last drop. Cycloplegic autorefraction was performed with an autorefractor (RK-F1; Canon, Tokyo, Japan) that generated five reliable refractions for each eye. The median reading was used in analysis.

An optical biometer (IOLMaster; Carl Zeiss Meditec, GmbH, Oberkochen, Germany) was used to measure $\mathrm{Al}$, corneal radius of curvature, and anterior chamber depth. Al was measured as the distance from the anterior comeal vertex to the retinal pigment epithelium along the fixation line. Measurements of AL by using partial coherence interferometry (IOLMaster) have been shown to be more precise and repeatable than those obtained with ultrasound. ${ }^{25}$ Each AL measurement was assessed for validity by the signal-to-noise ratio $(S N R)$, with $S N R \geq 2,0$ indicating a reliable result. The average of five valid AL measurements was used in analysis. Corneal radius of curviture was measured along the flattest and steepest meridians. Three consistent keratometry measurements (each of which was the result of five measurements), and the average of five valid anterior chamber depth measurements were used in analysis. Keratometry readings were consistent if corneal astigmatism did not vary by more than $0.1 \mathrm{D}$ between readings, and the astigmatic axis varied by $5^{\circ}$ or less for astigmatism of at least $0.5 \mathrm{D}$ and $10^{\circ}$ or less for astigmatism of less than $0.5 \mathrm{D}$. Anterior chamber depth measurements were valid if individual measurements varied by not more than $0.15 \mathrm{~mm}$.

\section{Questionnaire Data}

participants completed a 65 -item questionnaire that included information about time spent on near work and outdoor activities (available at http://www.cvr.org.all/sms.htm). The hours of near work performed per day outside school was the sum of time spent in each of the following activities: drawing, painting and/or writing, school homework, reacling books for pleasure, and playing hand-held computer games. The time spent on near work activity per week was the weighted sum of neilr work hours on a school weekdaly and a school weekend. 'Time spent on outdoor activities per week was the total time spent out of doors, weighted by weekday and weekend. Parents completed a comprehensive 173-item questionnaire that included sociodemographic information including ethnicity and parental characteristics, such as highest education level, occupation, and any spectacle or contact lens use. Parents who used spectacles were asked to indicate the age at first use and the purpose of use (distance viewing only, near work only, or both distance viewing and near work). When parents reported using spectacles, spectacle prescriptions were obtained from parents or their prescribers, where possible. Where prescriptions were not available, the spectacle-use questions in the parental questionnaire were used to determine whether parents were myopic or nonmyopic, as previously reported by Mutti et al. ${ }^{1 / 4}$

\section{Validation of the Spectacle-Use Questions}

The spectacle-use questions used by Mutti et al. ${ }^{1 / 4}$ were validated by Walline et al. ${ }^{26}$ in a clinical setting. We performed an additional validation analysis, as respondents in our study were from a nonclinical school-based setting (Ip JM et al., manuscript submitted). Briefly, spectacle prescriptions collected from parents of participants $(n=720)$ were used to determine the accuracy of the spectacle-use questions, which predicted myopia when spectacles were used for distance viewing only or when the age at first spectacle use for both distance viewing and near work was 30 years or younger. Otherwise parents were classified as nonmyopic. The age cutoff of 30 years was deter- mined from a receiver operating characteristic (ROC) curve, in which the true-positive rate (sensitivity) was plotted against the false-negative rate (1-specificity) for a range of age cutoffs for first spectacle use $(5-50$ years). The point farthest from the diagonal of the ROC curve (age cutoff, 30 years) represented the best predictive accuracy of the spectacle-use data for determining myopia (sensitivity $=0.89$; speci ficity $=0.83$ )

\section{Definitions}

Spherical equivalent refraction (SER, sphere $+1 / 2$ cylinder) categories included myopia (SER $\leq-0.50 \mathrm{D})$, emmetropia $(-0.50$ to $+0.50 \mathrm{D})$ and hyperopia ( $\geq+0.50 \mathrm{D}$ ). Astigmatism was defined as cylinder $\geq 1.00 \mathrm{D}$. Similar refraction categories (myopia, emmetropia, and hy peropia) were defined in parents with available prescriptions, with further classification of myopia as low $(\mathrm{SE}-3.00$ to $\leqslant-0.50 \mathrm{D})$ moderate $(-6.00$ to $\leq-3.00 \mathrm{D})$, or high $(\leq-6.00 \mathrm{D})$, which are generally consistent with definitions suggested by the American Acad emy of Ophthalmology. ${ }^{27}$ Ethnicity was classified on the basis of selfidentification by the parents, combined with information about the place of birth of the child. The child was attributed an ethnic origin only if both parents shared that ethnic origin. Otherwise, the children were placed in the mixed category. The ethnic categories used by the present study (European Caucasian, East Asian, Souch Asian, Middle Eastern, Pacific Islander, Indigenous Australian, African, South Ameri can) are consistent with the Australian Standard Classification of Cul tural and Ethnic groups ${ }^{28}$ and with the genetic relatedness of humath populations defined by modern molecular biology. ${ }^{29}$ The term Eist Asian covers people originating from China, Myanmar, Thalland, Lios. Cambodia, Vietnam, Malaysia, Singapore, Indonesia, Philippines, Japan, and Korea. The broad classification of East Asian was used nather than separate Northeast Asian and Southeast Asian categories because of the difficulty of classifying people who identify themselves as Chinese but who are derived from both of these branches.

\section{Data Analysis}

Data were analyzed with commercial software (Statistical Analysis System, ver. 9.1.3; SAS Institute, Cary, NC). Parental myopia was categorized by the number of myopic parents (none, one, or two), of by a dichotomous variable (no myopic parents or at least one). Tertiles of near work were constructed based on data for the whole sample. Mixed models and generalized estimating equations were used to examine associations and subgroup differences, adjusting for the ef fects of cluster sampling. When cluster effects were not significant. $t$-tests and $\chi^{2}$ tests were used. Refractive error and AL were modeled as a function of parental myopia and near-work hours, after adjustment for age, gender, height, ethnicity, and outdoor activity, using both analysis of covariance and regression models with interaction terms. All confidence intervals (CIs) are $95 \%$.

\section{ReSULTS}

\section{Population Demographics}

Of 3144 eligible children, 2367 had parental permission to participate (75.3\% response) and 2353 children were available for complete examination. The mean age of participants was 12.7 years (range, $11.1-14.4$ ); $49.4 \%$ were girls. The ethnic origins of participants included European Cancasian (60.0\%) and East Asian (15.0\%), and other ethnic groups that were not separately analyzed.

\section{Parental Myopia Status}

The characteristics of the children with data on parental myo pia included in the analysis $(n=1781)$ were similar to the children without data on parental myopia $(n=572)$ by age $(P=0.7)$ and SER $(P=0.2)$ (Table 1$)$. The sample included for analysis had a higher proportion of boys $(51.8 \%$ vs $46.9 \%, P$ 
TAmE 1. Chatacteristics of Children Aged 12 Years with and without Parental Myopia Data

\begin{tabular}{|c|c|c|}
\hline Variable & $\begin{array}{c}\text { Parental Data } \\
\text { Available } \\
(n=1781)\end{array}$ & $\begin{array}{c}\text { No Parental Data } \\
\text { Available } \\
(n=572)\end{array}$ \\
\hline Male gender (\%) & 51.8 & 46.9 \\
\hline \multicolumn{3}{|l|}{ Ethnicity (\%) } \\
\hline European Catucasinn & 62.1 & 53.3 \\
\hline East Asian & 14.6 & 16.5 \\
\hline Other & 23.3 & 30.3 \\
\hline Age, $y$ (mean $\neq \mathrm{SD})$ & $12.7(0.4)$ & $12.7(0.4)$ \\
\hline $\mathrm{SER}, \mathrm{D}($ mean $\pm \mathrm{SD})$ & $0.52(1.29)$ & $0.52(1.36)$ \\
\hline \multicolumn{3}{|c|}{$\begin{array}{l}\text { Near work and outdoor activity } \\
\text { (mean } \pm \text { SD) }\end{array}$} \\
\hline Near work $(\mathrm{h} / \mathrm{wk})$ & $18.8(10.2)$ & $19.3(10.7)$ \\
\hline Outdoors (h/wk) & $12.3(7.5)$ & $12.0(7.8)$ \\
\hline
\end{tabular}

$0.04)$ and consisted of more European Caucasian children (62.1\% vs. $53.3 \%, P=0.0006)$ and fewer East Asian children (14.6\% vs. $16.5 \%)$; however, there were no significant differences in the time spent on near work or outdoors (both $P=$ 0.2).

Between $48 \%$ and $50 \%$ of parents in the study who answered the questions on spectacle use reported not using spectacles. Of all parents who were identified as myopic (436 mothers and 355 fathers), the majority (73.6\% of mothers and $76.9 \%$ of fathers) were determined by questionnaire data only.
Myopia prescriptions confirming questionnaire data were avail able for $23 \%$ to $26 \%$ of parents.

The proportion of children with no, one, or two myopic parents was $62.7 \%(n=1116), 30.3 \%(n=539)$, and $7.1 \%(n$ $=126$ ), respectively. When stratified by ethnicity, the propor tion of children with two myopic parents was lower in the European Caucasian than in the East Asian subgroup $(5.2 \%$ vs $17.4 \%$ ). The proportion with no myopic parents was higher in the European Caucasian than in the East Asian group $61.7 \%$ vs $55.6 \%)$; as were the proportion with one myopic parent $(33.1 \%$ vs. $27.0 \%, \chi^{2}, P<0.0001$ ).

\section{Parental Myopia and Refraction in the Children}

The prevalence of myopia increased from $7.6 \%$ in the children with no myopic parents to $14.9 \%$ in those with one myopic parent and $43.6 \%$ in those with two myopic parents (Table 2 ) whereas the prevalence of hyperopia decreased $(76.0 \%, 65.2 \%$ and $41.9 \%$ ).

Compared with the children with neither parent myopic. the unadjusted odds ratio (OR) for myopia was significantly increased in the children with one myopic parent (OR 1.9;95\% CI 1.5-2.3) or two (OR 5.6,95\% CI 3.5-8.8; Table 3). After adjustment for environmental and demographic factors, the odds of childhood myopia were 2.3 when one parent was myopic and 7.9 when two parents were myopic. The odds of myopia were substantially higher among the children of East Asian than among those of European Caucasian ethnicity aftet adjustment (OR $12.3,95 \%$ CI $8.1-18.5$ ). In multivariate analy

TABLE 2. Association between Parental Myopia and Proportion with Refractive Error, SER, AL, and Hours Spent on Near Work, among 12-Year-Old Children

\begin{tabular}{|c|c|c|c|}
\hline \multirow[b]{2}{*}{ Variable/Ethuic Group } & \multicolumn{3}{|c|}{ Number of Myopic Parents } \\
\hline & None & One & Two \\
\hline \multicolumn{4}{|l|}{ Proportion with refractive error, $\%$ (CD) } \\
\hline \multicolumn{4}{|l|}{ Myopin" } \\
\hline All & $7.6(4.6-10.6)$ & $14.9(8.7-21.1)$ & $43.6(24.9-62.2)$ \\
\hline European Caucasian & $3.0(2.0-3.9)$ & $6.0(2.9-9.1)$ & $17.2(6.5-279)$ \\
\hline East Asian & $28.2(14.9-41.5)$ & $48.6(39.3-57.8)$ & $77.3(69.8-84.8)$ \\
\hline \multicolumn{4}{|l|}{ Hyperopiat } \\
\hline All & $76.0(70.3-81.8)$ & $65.2(56.6-73.7)$ & $41.9(23.8-60.0)$ \\
\hline European Calucasian & $86.9(83.8-90.0)$ & $75.9(69.8-82.0)$ & $62.1(47.0-77.1)$ \\
\hline East Asian & $39.4(30.8-48.1)$ & $24.3(17.5-31.0)$ & $11.4(4.9-178)$ \\
\hline \multicolumn{4}{|l|}{ Emmetropia } \\
\hline All & $16.4(12.3-20.5)$ & $19.9(14.9-25.0)$ & $14.5(10.9-18.2)$ \\
\hline European Caucasian & $10.2(6.9-13.5)$ & $18.1(12.0-23.3)$ & $20.7(10.2-31.2)$ \\
\hline East Asian & $32.4(21.3-43.5)$ & $27.1(19.3-34.9)$ & $11.4(5.6-17.1)$ \\
\hline \multirow{2}{*}{\multicolumn{4}{|c|}{$\begin{array}{l}\text { Refraction and axial length, mean (CD) } \\
\text { SER (D) }\end{array}$}} \\
\hline & & & \\
\hline All & $0.70(0.55-0.85)$ & $0.34(0.16-0.52) 8$ & $-0.55(-0.22-0.13) \mathrm{s}$ \\
\hline European Caucasian & $0.99(0.93-1.05)$ & $0.70(0.61-0.78) \S$ & $0.32(-0.05-0.70)$ \\
\hline East Asian & $-0.06(-0.32-0.19)$ & $-0.91(-1.34--0.48)$ & $-2.29(-293--1.64) 8$ \\
\hline \multicolumn{4}{|l|}{ Axial length (mm) } \\
\hline All & $23.32(23.22-23.42)$ & $23.44(23.33-23.55) 5$ & $23.62(23.30-23.93) \|$ \\
\hline European Caticasian & $23.18(23.11-23.25)$ & $23.27(23.16-23.38)$ & $23.18(2300-23.37)$ \\
\hline East Asian & $23.63(23.47-23.78)$ & $24.05(23.84-24.27) \|$ & $24.48(24.17-24.79) 9$ \\
\hline \multirow{2}{*}{\multicolumn{4}{|c|}{$\begin{array}{l}\text { Time spent on near work (h/wk), mein (SEM) } \\
\text { Near work }\end{array}$}} \\
\hline & & & \\
\hline All & $18.9(0.8)$ & $19.3(0.7)$ & $19.1(0.8)$ \\
\hline European Caucasian & $18.3(0.8) \pi$ & $19.0(0.9)$ ข & $21.3(1.1)$ \\
\hline East Asian & $21.5(0.9)$ & $23.4(0.8)$ & $22.9(0.7)$ \\
\hline
\end{tabular}

SER $\leq-0.50 \mathrm{D}$

$+5 \mathrm{ER} \geq+0.50 \mathrm{D}$.

$\neq$ SER from $>-0.50$ to $<+0.50 \mathrm{D}$

$\circlearrowleft P<0.0001$, no-myopic-parent group used as the reference, with adjustment for age, height, gender, near work, and outcloor activity. Analysis for all children was also adjusted for ethnicity.

$\| P \leq 0.05$, no-myopic-parent group used as the reference, after adjustment

If $P<0.05$, two-myopic-parents group used as the reference. 
TABLE 3. Univariate and Multivariate Adjusted ${ }^{*}$ OR for Myopia in the Children with Myopic Parents, Compared with Those with No Myopic Parents

\begin{tabular}{lll}
\hline & \multicolumn{2}{c}{ Odds Ratio (CI) } \\
\cline { 2 - 3 } & \multicolumn{1}{c}{ Univariate } & Multivariate \\
\hline All children & & \\
$\quad$ One myopic parent & $1.9(1.5-2.3)$ & $2.3(1.8-2.9)$ \\
$\quad \begin{array}{l}\text { Two myopic parents } \\
\text { European Caucasian children }\end{array}$ & $5.6(3.5-8.8)$ & $7.9(5.0-12.4)$ \\
$\quad \begin{array}{l}\text { One myopic parent } \\
\text { Two myopic parents }\end{array}$ & $2.1(1.2-3.6)$ & $1.7(1.1-2.6)$ \\
East Asian children & $6.8(3.3-14.2)$ & $6.0(2.8-13.1)$ \\
$\quad$ One myopic parent & $2.1(1.1-4.3)$ & $2.3(1.1-4.9)$ \\
Two myopic parents & $5.5(2.7-11.5)$ & $8.8(3.3-23.4)$ \\
\hline
\end{tabular}

*Adjusted for age, gender, near work, and time spent outdoors. Analysis for all children was also adjusted for ethnicity.

ses, the odds of myopia did not change significantly with increasing near work in hours per week (OR 1.01,95\% CI $0.99-1.03)$, but odds were slightly reduced with increasing outdoor activity (OR $0.96,95 \% \mathrm{CI} 0.94-0.98$ ).

Parental myopia was associated with increasingly myopic SER and longer AL in the children (Table 2). Mean refraction in the children with one myopic $(+0.34$ D) or two myopic $(-0.55 \mathrm{D})$ parents was significantly more negative than in the children with no myopic parents $(+0.70 \mathrm{D})$, after adjustment for age, gender, height, ethnicity, near work, and outdoor activity (both $P<0.0001$ ). These trends in SER with parental myopia were similar before and after adjustment for near work and outdoor activities (both $P_{\text {trend }}<0.0001$ ).

Within both the European Caucasian and the East Asian ethnic groups, there were similar trends of higher myopia prevalence and more myopic SER with increasing number of myopic parents (Table 2; Figs. 1A, 1B). After adjustment for demographic and environmental factors, the trends in myopia prevalence were significant in the East Asian subgroup $(P=$ 0.01 ) and of borderline significance in the European Caucasian subgroup $(P=0.055)$, but the trends in SER were statistically significant in both ethnic groups (both $P<0.0001$ ). In multivariate analyses, the interaction between parental myopia (having at least one myopic parent versus no myopic parents) and ethnicity was significant for the continuous outcome variable SER $(P<0.0001)$, but not for the categorical variable myopia (present or absent; $P=0.2$ ). The model variates parental myopia and ethnicity were both significantly associated with myopia as a categorical variable (both $P \leq 0.003$ )

\section{AL in the Children with and without Myopic Parents}

Overall, compared with the children with no myopic parents, the mean AL in the children with either one myopic parent $(P<0.0001)$ or two $(P=0.02)$ was longer, with a significant trend after adjustment for demographic and environmental factors such as age, gender, ethnicity, near work, and outdoor activities $\left(P_{\text {trend }}<0.0001\right)$. This trend was also evident in separate analyses of the children of East Asian ethnicity $(P<$ $0.0001)$, but not in those of European Caucasian ethnicity $(P=$ 0.07 ; Fig. 1C). A significant interaction of ethnicity with myopia in at least one parent for the children's AL was confirmed in multivariate analysis $(P<0.00001)$. The eyes of the children of East Asian ethnicity were longer than those of the children of European Caucasian ethnicity, irrespective of parental myopia (Table 2), consistent with the higher prevalence of myopia in the East Asian group.
We examined the AL of the nonmyopic children by using the same cutoff as was used by Zadnilk et al., ${ }^{19} \mathrm{SE}=-0.75 \mathrm{D}$ $(n=1582)$, to determine whether the nonmyopic children with myopic parents had longer eyes. In this analysis, mean $\mathrm{AL}$ in the children with either one or two myopic parents was not significantly different from that in the children with no myopic parents after adjustment $(P=0.06$ and $P=0.5$. respectively). When only data for the children without sig. nificant ametropia $(-0.50 \mathrm{D}<\mathrm{SE}<+2.00 \mathrm{D} ; n=1369)$ were analyzed, AL in the children with myopic parents and in the children without myopic parents was still not signif icantly different $(P=0.1$ for one myopic and $P=0.08$ for two myopic parents).

\section{a}
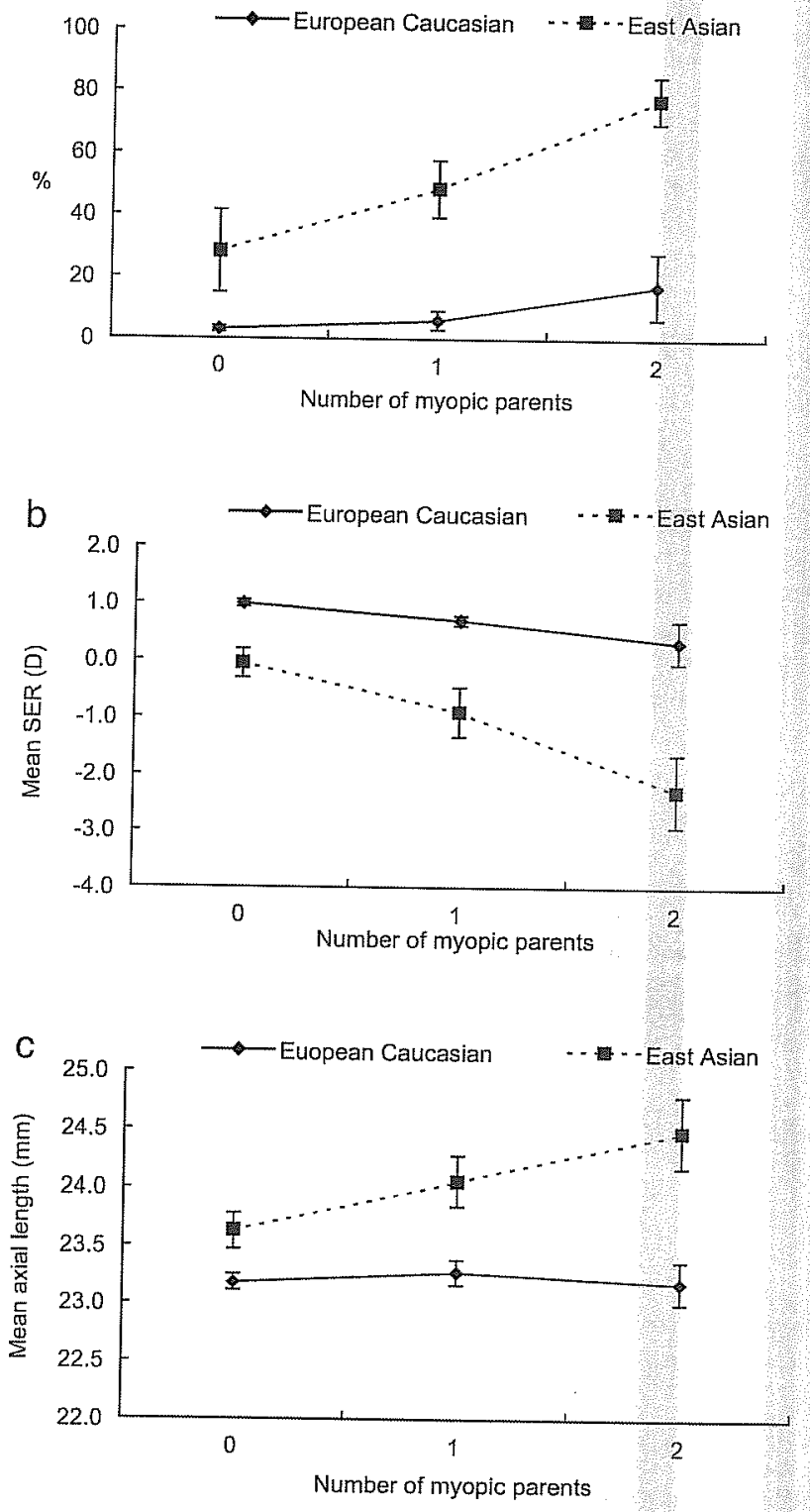

FIGURE 1. Association of increased number of myopic parents with (A) proportion of children with myopia, (B) mean childhood SER, and (C) mean AL, in the children of East Asian and European Caucasian ethnicity. Error bars, 95\% CI. 
TAble 4. Association of Severity of Parental Myopia with Mean SER and AL in the Children

\begin{tabular}{|c|c|c|}
\hline \multirow[b]{2}{*}{ Level of Parental Myopia" } & \multicolumn{2}{|c|}{ Mean (CI) } \\
\hline & SER (D) & Axial Length (mm) \\
\hline No myopia $($ SER $>-0.50 \mathrm{D})$ & $+0.78(0.48-1.06)$ & $23.21(23.04-23.39)$ \\
\hline Mild myopia $(-3.00 \mathrm{D}<\mathrm{SER} \leq-0.50 \mathrm{D})$ & $+0.12(-0.41-0.64)$ & $23.40(23.15-23.65)$ \\
\hline Moderate myopia $(-6.00 \mathrm{D}<\mathrm{SER} \leq-3.00 \mathrm{D})$ & $-0.45(-1.26-0.36)$ & $23.75(23.35-24.15) \dagger$ \\
\hline High myopia (SER $\leq-6.00 \mathrm{D}$ ) & $-1.43(-2.94-0.08)$ & $24.09(23.32-24.87) \dagger$ \\
\hline
\end{tabular}

\section{Correlation of Level of Parental Myopia with Childhood Refraction and AI}

The effect of level of parental myopia on the refraction and $\mathrm{AL}$ of their children, as well as the association with the odds of childhood myopia, is shown in Tables 4 and 5 . The mean unadjusted SER in the children with at least one highly myopic parent $(-1.43 \mathrm{D})$ or at least one moderately myopic parent $(-0.45 \mathrm{D})$ was lower than in the children with no myopic parents $(+0.78 \mathrm{D}$, both $P<0.05$; Table 4$)$. Unadjusted analyses did not show any differences in childhood refraction between the children with at least one myopic parent and those with no myopic parents $(P=0.08)$. In multivariate models (with adjustment for age, gender, ethnicity, near work, outdoor activity, and number of myopic parents), there were no significant differences in SER between the four groupings for parental myopia (no myopia, mild myopia, moderate myopia, high myopia), although a moderate or high level of myopia in at least one parent was a significant predictor of $\mathrm{AL}$ in the children $(P<0.05)$. However, when three groupings were used for parental myopia (no myopia, mild myopia, and moderate to high myopia), moderate to high myopia in at least one parent was associated with a significantly lower SER $(P=0.03)$ and longer AL $(P<0.0001)$ compared with no parental myopia. The SER in the children correlated moderately with the SER in both their mothers (correlation coefficient, $r=0.37, P<$ $0.0001)$ and fathers $(r=0.30, P<0.0001)$.

\section{Childhood Refraction and Time Spent on Near Work}

Overall, the mean SER in all the children was $+0.55,+0.54$, and $+0.40 \mathrm{D}$ for the lowest, middle, and highest tertiles of near work, respectively. The trends in mean SER after adjustment for age, gender, ethnicity, and outdoor activity, stratified by parental myopia are shown in Table 6. In the European Caucasian ethnic group, SER was not associated with greater levels of near work, and there was no significant trend after adjust-

Table 5. Odds of Myopia in the Children by Level of Parental Myopia, Compared with the Children with No Myopic Parent

\begin{tabular}{lcc}
\hline $\begin{array}{c}\text { Level of Parental } \\
\text { Myopia }\end{array}$ & $\begin{array}{c}\text { Univariate } \\
\text { OR (CI) }\end{array}$ & $\begin{array}{c}\text { Multivariate-Adjusted } \\
\text { OR (CI) } \dagger\end{array}$ \\
\hline Mild myopia & $5.8(1.8-19.1) \ddagger$ & $6.4(1.5-27.8) \ddagger$ \\
Moderate myopia & $11.9(3.6-38.7) \ddagger$ & $10.2(2.6-40.1) \ddagger$ \\
High myopia & $27.2(8.1-91.1) \ddagger$ & $21.8(5.3-89.4) \ddagger$ \\
\hline
\end{tabular}

* Defined by the most myopic refraction of the two parents or by the refraction of the one available parent.

$\dagger$ Adjusted for alge, gender, ethnicity, near work, and outdoor activity.

$\$ P<0.05$ with no parental myopia as the referent. ment $(P=0.06$ for parental myopia and $P=0.1$ for no parental myopia). In the East Asian ethnic group, SER was not signifi cantly associated with increasing near work after adjustment, in either the children with parental myopia $(P=0.07)$ or those without parental myopia $(P=0.8$ ).

The proportion of the children with myopia and the odds of myopia in the two ethnic groups, stratified by the amount of near work and parental myopia, are shown in Table 7 . Possible interactions between near work and parental myopia were analyzed in a regression model, with the odds of myopia as the dependent variable. The interaction was not statistically signif icant in the overall sample $(P=0.3)$ or in the children of European Caucasian ethnicity $(P=0.9)$ but was significant in the East Asian children $(P=0.01)$. When SER was assigned as the dependent variable in a linear regression model, the interaction term (parental myopia $\times$ near work) was also not significant in the overall sample ( $P=0.6$ ) or in the European Caucasian group $(P=0.6)$. In the East Asian group, this interaction was statistically significant $(P=0.03)$, but near work was associated with a more hyperopic refraction in those with parental myopia.

\section{Discussion}

\section{Parental Myopia and Childhood Refraction}

In this population-based sample of 12-year-old school children, parental myopia was significantly associated with refraction in the whole sample, and in the children of both European and East Asian ethnicity. In general, the prevalence of myopia was higher and refraction was more myopic in the children with myopic parents, findings that are consistent with several previous studies, ${ }^{1-1,17,20,30}$ despite substantial study differences in other population characteristics, educational and physical environments, examination protocols, and statistical methods. In contrast, smaller studies among East Asian children by Fan et al. ${ }^{23}(n=594$, ages, $2.3-6.4$ years $)$ and Edwards ${ }^{31}(n=82$, age 12 years) reported no association of parental myopia with childhood myopia or refraction.

\section{Parental Myopia and Childhood AL}

An incremental increase in childhood AL associated with a greater number of myopic parents has been reported ${ }^{16,20}$, however, in the present study we observed only significant findings in children of East Asian ethnicity and not in children of European Caucasian ethnicity. Several factors may contribute to these findings. Children of European Caucasian origin may have a slower onset of myopia, as indicated by the much lower percentage of children with myopia (4.6\%) compared with their parents (21.8\%) in this study. In the East Asian subgroup, the proportion with myopia in the children was $39.5 \%$ compared with $30.9 \%$ in their parents. In our sample, 

TABLE 6. Mean SER in 12-Year-Old Children in Tertiles of Near-Work Hours per Week, Stratified by
Parental Myopia and Ethnicity

\begin{tabular}{|c|c|c|c|}
\hline \multirow[b]{2}{*}{ Near-Work Hours per Week } & \multicolumn{3}{|c|}{ Mean Spherical Equivalent Refraction," D (CI) } \\
\hline & All Children & $\begin{array}{l}\text { European } \\
\text { Caucasian }\end{array}$ & East Asian \\
\hline \multicolumn{4}{|l|}{ No myopic parents } \\
\hline Lowest tertile & $0.56(0.44-0.69)$ & $1.02(0.92-1.12)$ & $0.19(-0.04-0.43)$ \\
\hline Middle tertile & $0.48(0.37-0.59)$ & $1.02(0.93-1.11)$ & $-0.22(-0.57-0.12)$ \\
\hline Highest tertile & $0.38(0.21-0.55)$ & $0.86(0.70-1.01)$ & $-0.21(-0.65-0.22)$ \\
\hline$P$ for trend & 0.1 & 0.1 & 0.8 \\
\hline \multicolumn{4}{|l|}{ One or two myopic parents } \\
\hline Lowest tertile & $-0.37(-0.71--0.03)$ & $0.77(0.64-0.91)$ & $-2.75(-3.76--1.75)$ \\
\hline Middle tertile & $-0.21(-0.37--0.06)$ & $0.66(0.52-0.80)$ & $-1.33(-1.89--0.78)$ \\
\hline Highest tertilc & $-0.33(-0.37--0.08)$ & $0.52(0.35-0.68)$ & $-1.42(-2.25--0.60)$ \\
\hline$P$ for trend & 0.7 & 0.06 & 0.07 \\
\hline
\end{tabular}
ethnicity.

the proportion of children with myopia in both parents was substantially lower in the European Caucasian group compared with the East Asian group, and this difference could also result in a stronger association in the East Asian group.

\section{Eye Length in Children with Myopic Parents}

In a seminal paper, Zadnik et al. ${ }^{20}$ reported that nonmyopic children with myopic parents had longer eyes than those without myopic parents. We performed a similar analysis, firstly excluding the children with prevalent myopia (defined as in the report by Zadnik et al., SE of $-0.75 \mathrm{D}$ or less), and secondly including only those children with emmetropia, to maximize the chance that they were progressing to myopia. In both analyses, we found no association of refraction or AL with parental myopia; and thus, we were not able to confirm the finding that nonmyopic children with myopic parents had longer ALs. There are several differences between the two studies, however, including a larger group of children with East Asian ethnicity in the present study and a larger proportion of parents (47.2\%) with myopia in the Orinda study ${ }^{20}$ compared with the parents of both European Caucasian (21.8\%) and East Asian (30.9\%) ethnicity in Sydney. Our sample of children was derived from one school level (year 7 , age range, 11-14 years; mean age, 12.7 years) whereas in the Orinda study the ages of children ranged from 6 to 13 years. The prevalence of myopia in our sample at the age of 12 years (11.9\% for the total and $4.6 \%$ of the subsample with European Caucasian ethnicity) is also much lower than that reported in the Orinda study at a similar age (28\%)..$^{32}$ Although the poten tial impact of these differences is not clear, none seems to provide a simple explanation of the different outcomes in the two studies.

At one level, our failure to find an association between parental myopia and childhood AL is surprising, because the process of excessive axial elongation must be involved. ${ }^{33}$ One possibility is that in our sample of 12-year-old children, the progression to myopia was largely complete, and the nonmyopic children were not destined for development of myopia. This explanation is unlikely for several reasons. Many studies show that incident myopia and myopic progression continue to occur after the age of 12 years. ${ }^{1,6,34}$ In addition, the prevalence of myopia in the children of European Caucasian ethnicity in our sample was much lower than that for their parents. which suggests that there is likely to be considerable incident myopia in the future, an assumption that will be tested as longitudinal data are collected.

To examine the effects of age, the association between childhood AL and parental myopia in nonmyopic children was also assessed using the sample of younger children (predominantly aged 6 years; $n=879$ ) who were examined in the earlier phase of our study. This analysis was adjusted for age. gender, height, near work, and outdoor activity. Among this sample of children, which included for analysis only those without myopia according to the definition used by Zadnik et al. $^{20}(\mathrm{SER}>-0.75 \mathrm{D})$, there was no significant association between the number of myopic parents and mean childhood TABus 7. Odds of Myopia in the Children with One or More Myopic Parents, Compared with Those with No Myopic Parents, Stratified by
Tertiles of Near-Work Hours per Week and by Ethnicity

\begin{tabular}{|c|c|c|c|c|c|c|c|c|}
\hline \multirow{3}{*}{$\begin{array}{l}\text { Near-Work } \\
\text { Hours per } \\
\text { Week }\end{array}$} & \multicolumn{4}{|c|}{ European Caucasian ${ }^{*}$} & \multicolumn{4}{|c|}{ East Asian* } \\
\hline & \multirow[b]{2}{*}{$n$} & \multicolumn{2}{|c|}{ \% Myopia } & \multirow[b]{2}{*}{ OR $(\mathrm{CI}) \dagger$} & \multirow[b]{2}{*}{$n$} & \multicolumn{2}{|c|}{ \% Myopia } & \multirow[b]{2}{*}{$\mathrm{OR}(\mathrm{CI}) \mathrm{t}$} \\
\hline & & $\begin{array}{c}\text { Parental Myopia } \\
\text { Absent }\end{array}$ & $\begin{array}{l}\text { Parental Myopia } \\
\text { Present }\end{array}$ & & & $\begin{array}{c}\text { Parental Myopia } \\
\text { Absent }\end{array}$ & $\begin{array}{l}\text { Parental Myopia } \\
\text { Present }\end{array}$ & \\
\hline Lowest tertile & 373 & 2.4 & 4.7 & $2.1(0.7-6.8)$ & 48 & 9.4 & 75.0 & $18.2(3.9-89.0)$ \\
\hline Middle tertile & 355 & 2.4 & 5.6 & $2.5(0.9-6.8)$ & 91 & 38.0 & 65.0 & $2.6(0.9-7.1)$ \\
\hline Highest tertile & 302 & 5.2 & 10.9 & $2.2(1.1-4.4)$ & 106 & 33.0 & 52.0 & $1.4(0.6-3.1)$ \\
\hline$P_{\text {trend }}$ & & 0.07 & 0.045 & & & 0.3 & 0.02 & \\
\hline
\end{tabular}

"Parental myopia and near-work interaction were statistically significant in the East Asian $(P=0.01)$ but not in the European Caucasian $(P=$ $0.9)$ children.

† Adjusted for age, gender, and time spent outdoors. 
AL, both in the overall sample $(P=0.1)$ and in the children of East Asian ethnicity $(P=0.78)$. In the children of European Caucasian ethnicity separately, this association barely reached statistical significance $(P=0.0497)$. In this younger sample of nonmyopic children, an association of parental myopia with AL in the nonmyopic children was therefore not strong.

In the study by Fan et al., ${ }^{23}$ who performed a similar analysis of childhood $\mathrm{AL}$, there was also no association between nonmyopic AL and parental myopia. The children in the Fan study sample were younger (ages 2.3- 6.4 years) than in most other studies, and as most incident myopia appears during the school years, even in urban East Asia where the onset of myopia before schooling is now common, the impact of parental myopia may not have been cletectable at this young age. Another possible explanation of our failure to find a significant association between parental myopia and AL in nonmyopic children is that AL has only a moderate association with refraction, a finding confirmed in our 6-year-old sample (correlation coeffcient, $r=-0.33) .{ }^{35}$ The ratio of AL to corneal radius of curvature (AL/CR) correlated more strongly with refraction $(r$ $=-0.51$ ), possibly because it expresses the matching of AL to the optical power that underpins refractive error

When the same reasoning is used that children at risk of myopia would have longer eyes before the onset of myopia, and if risk were defined by ethnicity, it might be expected that nonmyopic children of East Asian origin would have longer eyes than would children of other ethnicities. However, in recently reported results from the extension of the Orinda study, the Collaborative Longitudinal Evaluation of Ethnicity and Refractive Error (CLEERE), it was found that the nonmyopic Asian children had shorter eyes than did the Hispanic children (Mutti et al. IOVS 2005;ARVO E-Abstract 4623). This finding was unexpected, as the prevalence of myopia has been reported to be higher among Asian children than among Hispanic children in the CLEERE study. ${ }^{36}$ Thus, the collected results in the literature suggest that there is no consistent relationship between $\mathrm{AL}$ in nonmyopic children and the risk of development of myopia.

\section{Interaction between Parental Myopia and Ethnicity}

There was no statistically significant association between parental myopia and $\mathrm{AL}$ in the children of European Caucasian ethnicity, but there was a strong association in those of East Asian ethnicity. The effects of parental myopia on SER in the two ethnic groups also appeared to be different, with statistical analyses confirming a significant interaction. It is not clear, however, whether these differences are related to genetic differences between the two ethnic groups, or to other factors such as different patterns of engagement in outdoor activity. Further investigation of the impact of outdoor activity on myopia in children and ethnic differences in patterns of engagement are warranted. Greater similarity in SER or AL in one ethnic group (e.g., European Cancasian) may dilute any associations with parental myopia. In the European Caucasian ethnic group, the standard deviations for SER and AL were 0.95 and 0.75 , respectively. Corresponding values for the East Asian group were 1.91 and 1.07, respectively. Another consideration is the markedly higher prevalence of myopia in children with East Asian ethnicity (39.5\% vs. $4.6 \%$ ), which may attenuate the significance of regression analyses. It is unclear whether the lower myopia prevalence in the European Caucasian ethnic group also accounts for the absence of any significant trends in SER with a greater number of myopic parents in this group

\section{Ethoicity and Myopia}

Differences in the prevalence of myopia with ethnicity in children and causes for such differences have been the topic of much discussion in the literature. In the present study, the proportion of children with myopia was markedly higher in the group of East Asian than in those of European Caucasian ethnicity. Although a genetic explanation of this finding cannot be excluded, possible environmental confounders, including the higher school performance of students of East Asian ethnicity in the Australian school system and differences in the amount of time spent outdoors, should be considered. In a study comparing the prevalence of myopia in age-matched children of specific Chinese origin in Sydney and Singapore (Rose KA, Morgan IG, Saw S-M, unpublished data, 2004), we found that the prevalence is almost 10 times higher in Singapore than in Sydney, despite almost identical proportions of parental myopia. This finding may point to the impact of environmental exposures, because the potential effects of ge netic differences from ethnicity and parental myopia have been minimized in this case. Although a proportion of myopia is clearly genetic, characteristically very early onset of high re fractive error, there is currently no conclusive evidence of genetic contributions to mild or moderate myopia, despite substantial evidence of effects from environmental expo sures. ${ }^{11,12,37}$ Among the specific lines of evidence supporting this conclusion are the rapid and marked changes in prevalence of myopia in Inuit and Eskimo populations ${ }^{38-70}$ and in urban East Asia in recent decades. ${ }^{4}$ Analyses of the Beaver Dam Eye Study ${ }^{41,{ }^{1} 2}$ also highlighted the impact of environment, including a higher correlation in refraction after adjustment for age, education, and gender in sibling pairs than in parent-child pairs, which share similar proportions of genes. Polygenic (or multifactorial) influences, which cover multiple small genetic and environmental effects, ${ }^{43}$ also appear to have a role in the etiology of myopia. The ultimate test of a genetic origin for some of these associations, however, can come only from more direct tests for genetic contributions, such as through genome wide scans.

\section{Near Work and Refraction in Children}

Despite support for evidence of environmental influences in myopia, we found no evidence to confirm an association of near work with SER and myopia in our study of 12-year-old children. We found no significant overall association between the number of myopic parents and the time children spent in near work, a finding consistent with that of Mutti et al., ${ }^{1 / 4}$ which suggests that the strong association between parental myopia and their children's myopia is not mediated by in creased near work. Near work, however, is only one possible environmental factor, and further adjustment for other quantifiable environmental factors may help to explain the impact of parental myopia.

\section{Gene-Environment Interaction in Parental Myopia and Near Work}

Given the negative findings for near work, the nonsignificant interaction between parental myopia and near work for SER or odds of myopia, both within the overall sample and within the two separate ethnic groups (European Caucasian and East Asian), is not surprising. From our study, it appears that inter actions between parental myopia (as a surrogate for genetic differences) and near work (as an environmental exposure) do not make a case for gene-environment interaction in myopia.

Much of the discussion on gene-environment interaction in myopia has interpreted different outcomes, such as the level of ametropia in different environments within a given group, as evidence of such interactions. However, a gene-environment interaction implies the differential response of different alleles or haplotypes to similar environmental exposures. 19 A differ ent phenotype depending on environmental exposures (as may 
be the case for myopia) is not in itself a gene-environment interaction. Evidence of relevant genetic homogeneity is necessary, with different responses to the environmental exposures of genetic subgroups. For more definitive evidence of a gene- environment interaction, differential environmental exposures such as age at onset of near work and outdoor activity must be ruled out.

\section{Strengths and Limitations of the Study}

Stratified random cluster sampling was used to obtain a large representative study population of year-7 children in the Sydney metropolitan area. Although systematic data could not be collected on nonparticipants because of ethical concerns, our sample was matched in ethnicity and gender to children of similar age in the Sydney metropolitan area. We cannot rule out a participation bias in refractive error and other eye conditions, although an informal assessment of patterns of spectacle use suggests that the contribution from this form of bias was probably rather small. Few studies have examined this issue in detail, but Zadnik et al. ${ }^{20}$ were able to compare the data from their sample of school children in Orinda, where the participation rate was between $40 \%$ and $50 \%$, with the results of school screening of all eligible subjects from a 1-year cohort. They concluded that it was unlikely that the choice to participate introduced a systematic bias that limited the generalizability of their results. Thus, with due caution, our results can be generalized to 12-year-old school children in the Sydney metropolitan area, and with appropriate weighting for different patterns of ethnicity, to other urban school populations in Australia. We have used standardized procedures at all schools and performed objective measures using autorefraction after cycloplegia with cyclopentolate and have used an instrument for biometry measurements that has high repeatability, the optical biometer (IOLMaster; Carl Zeiss Meditec, GmbH). ${ }^{-15,36}$

Limitations in our study include the reliance on the chil dren's estimate of time spent in near work and outdoor activity. Recall bias may have affected the accuracy of these estimates and the validity of the associations, although Saw et al. ${ }^{-4}$ ? validated a questionnaire on near work activities containing some common questions, against 24-hour diaries recording these activities, and found that it was accurate and reliable.

Questions of measurement error should be clarified. Measurements in the children were standardized and highly reproducible. Although questionnaire data were used to determine parental myopia status indirectly, the validation of the spectacle-use questions showed that this method of inferring parental myopia status is sensitive and specific. However, the questionnaire may not detect parents with low levels of myopia $(>-1.0 \mathrm{D})$, if no spectacles are used.

In addition, in this cross-sectional study, some children classified as nonmyopic may have myopia develop later, whereas others may not. This heterogeneity may have an impact on some of the associations. Longitudinal data are needed to deal with this question.

In conclusion, the findings from The Sydney Myopia Study clearly demonstrate a marked association of parental myopia with both the prevalence and the magnitude of refractive error among children, such that the odds of childhood myopia were significantly and incrementally higher with the number of myopic parents. Ethnic stratification of our data showed that the impact of parental nyopia on childhood refraction (spherical equivalent, proportion myopic and $\mathrm{AL}$ ) was markedly different between the European Caucasian and East Asian ethnicities. Near work, measured as hours per week, was evaluated as a possible environmental risk factor for myopia; however, we did not find a statistically significant association in this crosssectional study.

\section{References}

1. He M, Zeng J, Liu Y, Xu J, Pokharel GP, Ellwein LB. Refractive error and visual impaiment in urban children in southern china. Invest Opbthalmol Vis Sci. 2004;45:793-799.

2. Lin LL, Shih YF, Tsai $C B$, et al. Epidemiologic study of oculat refraction among schoolchildren in Tawan in 1995. Optom Vis Sci. 1999;76:275-281.

3. Fan DS, Lam DS, Lam RF, et al. Prevalence, incidence, and pro. gression of myopia of school children in Hong Kong. Invest Opb. thalmol Vis Sci. 2004; $45: 1071-1075$.

4. Lin LL, Shih YF, Hsiao CK, Chen CJ. Prevalence of myopia in Tilwanese schoolchildren: 1983 to 2000. An Acad Med Singa pore. 2004:33:27-33.

5. Goh PP, Abqariyah Y, Pokharel GP, Ellwein LB. Refractive error and vistal impaiment in school-age children in Gombak District. Malaysia. Opbthalmology. 2005;112:678-685.

6. Zhao J, Pan X, Sui R, Munoz SR, Sperduto RD, Ellwein LB. Refrac tive error study in children: results from Shunyi District, China Am J Opbthalmol. 2000;129:427-435.

7. Wu HM, Seet B, Yap EP, Saw SM, Lim TH, Chia KS. Does education explain ethnic differences in myopia prevalence? - a population based study of young adult males in Singapore. Optom Vis Sci $2001 ; 78: 234-239$.

8. Dayan $\mathrm{YB}$, Levin $A$, Morad $Y$, et al. The changing prevalence of myopia in young adults: a 13-year series of population-based prevalence surveys. Invest Ophthalmol Vis Sct. 2005;46:2760-2765

9. Sperduto RD, Seigel D, Roberts J, Rowland M. Prevalence of myo pia in the United States, Arcb Opbthalmol. 1983;101.405-407.

10. Saw SM, Chua WH, Wu HM, Yap E, Chia KS, Stone RA. Myopia gene-environment interaction. Ann Acad Med Singapore. 2000 $29: 290-297$

11. Saw SM. A synopsis of the prevalence rates and environmental risk factors for myopia. Clin Exp Optom. 2003;86:289-294.

12. Gilmartin B. Myopia: precedents for research in the twenty-first century. Clin Exp Opbthalmol. 2004;32:305-324.

13. Saw SM, Wu HM, Seet B, et al. Academic achievement, close up work parameters, and myopia in singapore military conscripts Br.J Opbthalmol. 2001;85:855-860.

14. Mutti DO, Mitchell GL, Moeschberger ML, Jones LA, Zadnik K. Parental myopia, near work, school achievement, and childrens refractive error. Invest Opbtbalmol Vis Sci. 2002;43;3633-3640.

15. Pacella R, Mclellan J, Grice K, Del Bono EA, Wiggs JL, Gwiazda JE. Role of genetic factors in the etiology of juvenile-onset myopia based on a longitudinal study of refractive errot. Optom $\mathrm{Fis} \mathrm{Sc}$. 1999;76:381-386.

16. Saw SM, Chua WH, Hong CY, et al. Nearwork in early-onset myopia. Invest Opbthalmol Vis Sci. 2002; $3: 332-339$.

17. Yap M, Wu M, Liu ZM, Lee FL, Wang SH. Role of heredity in the genesis of myopia. Opbthalmic Pbysiol Opt. 1993;13:316-319.

18. Goss DA, Cox VD, Herrin-Lawson GA, Nielsen ED, Dolton WA. Refractive error, axial length, and height as a function of age in young myopes. Optom Vis Sci. 1990;67:332-338.

19. Logan NS, Davies LN, Mallen EA, Gilmartin B. Anetropia and ocular biometry in a U.K. university student population. Optom Vis SCi. 2005;82:261-266.

20. Zadnik K, Satariano WA, Mutti DO, Sholtz RI, Adams AJ. The effect of parental history of myopia on children's eye size. IAMA. 1994. 271:1323-1327.

21. Chew SJ, Ritch R. Parental history and myopia: taking the long view. JAMA. 1994;272:1255.

22. Wallman J. Parental history and myopia: taking the long view JAMA. 1994;272:1255-1256.

23. Fan DS, Lam DS, Wong TY, et al. The effect of parental history of myopia on eye size of preschool children: a pilot study. Acta Ophthalmol Scand. 2005;83:492-496.

24. Ojaimi E, Rose $\mathrm{KA}$, Smith W, Morgan IG, Martin FJ, Mitchell P Methods for a population-based study of myopia and other eyc conditions in school children: the Syciney Myopia Study Ophlhat mic Epidemiol. 2005;12:59-69.

25. Connors R III, Boseman P III, Olson RJ. Accuracy and reproducibility of biometry using partial coherence interferometry. I Cata ract Refract Surg. 2002;28:235-238. 
26. Walline J, Zadnik $\mathrm{K}$, Mutti DO. Validity of surveys reporting myopia, astignatism, and presbyopia. Optom Vis Sci. 1996;73: 376-381.

27. Preferred Practice Patterns. San Francisco: American Academy of Ophthalmologists. Available at http://www.aao.org/education/ library/ppp/index.cfm/. Accessed April 2007.

28. Australian Siandard Classification of Culural and Ethnic Groups Canberra, Australia: 2005-6:document 1249.0; available at www.abs.gov.au. Accessed April 2007.

29. Cavalli-Sforza LL, Feldman MW. The application of molecular genetic approaches to the study of human evolution. Nat Genet. 2003;33(suppl)266-275.

30. Saw SM, Carkeet A, Chia KS, Stone RA, Tan DT. Component dependent risk factors for ocular parameters in Singapore Chinese children. Opbthalmology. 2002;109:2065-2071.

31. Edwards $\mathrm{MH}$. Effect of parental myopia on the development of myopia in Fong Kong Chinese. Opbthalmic Pbysiol Opt. 1998;18 $477-483$.

32. Zadnik K. The Glenn A. Fry Award Lecture (1995). Myopia development in childhood. Optom Vis Sci. 1997;74:603-608.

33. Thorn F, Gwiazda J, Held R. Myopia progression is specified by a clouble exponential growth function. Optom Vis Sci. 2005;82: 286-297.

34. Maul E, Barroso S, Munoz SR, Sperduto RD, Ellwein LB. Refractive Error Study in Children: results from La Florida, Chile. $A m I$ Ophthalmol. 2000;129:445-454.

35. Ojaimi $\mathrm{E}$, Rose $\mathrm{KA}$, Morgan $\mathrm{IG}$, et al. Distribution of ocular biometric parameters and refraction in a population-based study of Australian children. Invest Ophtbalmol Vis Sci. 2005;46:24782754 .

36. Kleinstein RN, Jones LA, Hullett $S$, et al, Refractive error and ethnicity in children. Arcb Ophthalmol. 2003;121:1141-1147.
37. Morgan IG. Rose KA. How genetic is school myopiar Prog Retin Eye Res. 2005;24:1-38

38. Bear JC, Richler A, Burke G. Nearwork and familial resemblances in ocular refaction: a population study in Newfoundland. Clin Genet. 1981;19:462-472.

39. Young FA, Leary GA, Baldwin WR, et al. The talnsmission of refractive errors within eskimo families. An $J$ optom Arch Am Acad Optom. 1969;46:676-685.

40. Alsbirk PH. Refraction in adult West Greenland Eskimos: a popu lation study of spherical refractive errors, including oculometitic and familial correlations. Acta Opbthalmol (Copenb). 1979;57:84 95.

41. Lee $\mathrm{KE}$, Klein $\mathrm{BE}$, Klein R, Fine JP. Aggregation of refractive erro and 5-year changes in refractive error among families in the Beaver Dam Eye Study. Arcb Opbthalmol. 2001;119:1679-1685.

42. Klein AP, Duggal P, Lee KE, Klein R, Bailey-Wilson JE, Klein BE Support for polygenic influences on ocular refractive error. Inves Ophthalmol Vis Sci. 2005;46:442-446.

43. Jarvik GP. Statistical genetics '98: complex segregation analysesuses and limitations. Am I Hum Genet. 1998;63:942-916.

44. Ottman R. An epideniologic approach to gene-environment inter action. Genet Epidemiol. 1990;7:177-185.

45. Santodomingo-Rubido J, Mallen EA, Gilmartin B, Wolfisohn JS, A new noncontact optical device for ocular bionetry. BrT Opbthat mol. $2002 ; 86: 458-462$.

46. Carkeet A, Saw SM, Gazzard G, Tang W, Tan DTH. Repentability of IOLMaster Biometry in children. Optom Vis Sci. 2004:81:829-834

47. Saw SM, Nieto FJ, Kat $z$ J, Chew SJ. Estimating the magnitude of close-up work in school-age children: a compatison of question naire and diary instruments. Opbtbalmic Epidemiol 1999;6:291301 